\title{
Improvement of drag model for non-burning firebrand transport in Fire Dynamics Simulator
}

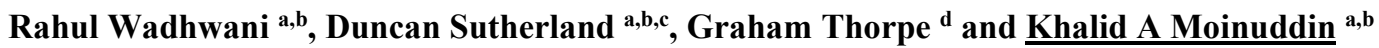 \\ ${ }^{a}$ Centre for Environmental Safety and Risk Engineering, Victoria University, Melbourne, Australia \\ ${ }^{b}$ Bushfire and Natural Hazards CRC, Melbourne, Australia \\ ${ }^{c}$ School of Science, University of New South Wales, Canberra, Australia \\ ${ }^{d}$ College of Engineering and Science, Victoria University, Melbourne, Australia \\ Email: khalid.moinuddin@vu.edu.au
}

\begin{abstract}
Firebrands play a crucial role in increasing the severity of wildfires by driving fire growth, damaging structures, and starting new fires. Predicting the transport of firebrands and their propensity to ignite new fires is of significant interest to fire communities. Developing an operational firebrand transport sub-model from the field studies is cumbersome, expensive, and has significant associated risks to equipment, community and firefighters. Physics-based models have the potential to assist in the development of such firebrand transport sub-models which can be utilised to improve the efficacy of existing operational fire models. The present study showcases one of the initial works carried out in the development of such a physics-based firebrand model. The work utilises Fire Dynamics Simulator (FDS), a commonly used open-source physicsbased fire model. The Lagrangian particle sub-model of FDS is used to simulate the transport of firebrand particles. The Lagrangian sub-model is generally used to model the transport of droplets and mist and has been extensively validated. However, the validation of this sub-model for the transport of solid particles such as firebrands is limited. The issue is exacerbated when particles are of a non-spherical shape and can undergo complex reactions over their transport such as burning.

In this work, we utilise a firebrand generator prototype that produces a uniform Lagrangian shower of nonburning idealised firebrands. A set of in-house experiments are conducted to study the transport of three isometric shapes of non-burning firebrands i.e. cubiform, cylindrical and square-disc. These sets of experiments are used to quantify the efficacy of the inbuilt particle drag model of FDS and suggest potential alternative drag models that can be employed without loss of computational speed, major amendment in the fire model, are applicable to a wide range of particles shapes, and potentially improved prediction. In general, it is found that the suggested alternative Haider and Levenspiel drag model improves the estimation of firebrand distribution in terms of peak location, maximum and minimum longitudinal distribution with exception to cubiform particles for peak location. The exception is mainly due to inherent error association with the alternative drag model in overestimating the drag coefficient. For other situations, Haider and Levenspiel drag model shows either an improvement or stays the same. However, the study found that the existing point particle assumption to represent particles in FDS is not suited to estimate the lateral spread of firebrands especially when the secondary motion of a particle on its axis is involved such as cylindrical and square-disc particles. Our studies found, the lateral spread is found to be in the range of $\sim 5-15 \%$ thinner compared to its experimental width for cylindrical particle distribution. For the square disc, it is not possible to quantify such differences due to the computational limit associated with our present study. It can be qualitatively suggested that it is found to be more than cylindrical particles. A further set of experiments and their numerical validation is required to ascertain the above finding, especially with different sizes, isometric and non-isometric shape, the speed of firebrand particles and burning process to establish the efficacy of a particular drag model for firebrand transport.
\end{abstract}

Keywords: Fire Dynamics Simulator (FDS), firebrand particles, Lagrangian particle, firebrand generator, drag models 


\section{INTRODUCTION}

Every year billions of dollars are lost to wildfire in countries like the US, Canada, and Australia (Ronchi et al., 2017). Recent wildfires such as the 2019-20 Black Summer in Australia, the 2019-20 Amazon fire in Brazil, the 2019 Californian wildfires in the USA, the ongoing 2021 Evia Island fire in Greece are the prominent incidences causing uncountable damage to the ecosystem with economic damage crossing billions of dollars. These wildfires are also associated with the massive evacuation of communities which created another challenge for fire and emergency services. A major contributor to the severity of these wildfires is the production of firebrands and the resulting ignitions, which assist in increasing the rate of fire spread, ignition of new fires, and damages the structures at the wildland-urban-interface (WUI).

Firebrands are burning pieces of twig, leaf, seed, and bark material that travel along with the wind and ignite the vegetation ahead of the fire front. The ignition caused by the transport of firebrands is called spotting and can be classified based on the distance travelled by firebrands as either: (1) short-range $(<750 \mathrm{~m}),(2)$ mediumrange (1-5 km), and (3) long-range (>5km) spotting (Cruz et al., 2015). In short-range spotting, the firebrands travel along with the wind with little to no lofting and can travel up to $750 \mathrm{~m}$. Most of the short-range firebrands are in flaming (as opposed to smouldering) states and are just broken material from trees. The effect of the firebrands is incorporated using the Huygens' wavelet principle model in operational wildfire models such as FARSITE, PROMETHEUS, and PHOENIX (Sullivan, 2009b). In medium and long-range spotting, firebrands lofted into the convective air column may travel from more than a kilometre. These firebrands are typically burned off and usually in the glowing (smouldering combustion) state (Ellis, 2012).

Most of the research (Ellis, 2012; Fernandez-Pello, 2017; Manzello et al., 2020) in the last decade or so focuses on long-range spotting which causes significant losses in a bushfire. The short-range firebrands contribute to increasing the rate of fire spread by causing spotfires that coalesce with the primary fire front. There is very limited significant research carried out in understanding the phenomena of short-range spotting. It has been argued that poor prediction of firebrand transport and spot is a major reason for the under-prediction of fire models used by emergency services (Cruz et al., 2015).

Fire dynamics simulator (FDS) developed by the National Institute of Standards and Technology (NIST) is one of the most used open-source physics (Computational Fluid Dynamics (CFD))-based fire models (McGrattan et al., 2015; Sullivan, 2009a). FDS solves a thermally driven Navier-Stokes equation to simulate the propagation of fire. A Lagrangian particle model, one of the sub-models of FDS, is used to simulate the transport of particles in the flow field. The model is extensively verified and validated for liquid particles like droplets and mist (Mahmud et al., 2016). However, verification and validation for the transport of solid particles are very limited. Wadhwani et al. (2017) attempted to verify the applicability of the inbuilt Lagrangian particle model of FDS ver. 6.2.0 (McGrattan et al., 2015) for the transport of non-burning firebrands. We observed that FDS inbuilt model under-predicts the spatial distribution of the cubiform and cylindrical firebrand particles. It was anticipated that the simulation did not account for the secondary motion of a particle on its axis due to its shape and thus providing a higher drag force on the particles. The particle model treats particles as point particles that do not account for any rotation on its axis and are only translated due to shear force. Furthermore, the inbuilt drag model is limited to only two shapes of particles viz. spherical and cylindrical which limits its application for firebrand transport research.

The present work focuses on finding an alternative drag model which is effective to a wide range of isometric shapes and fit in the current framework of FDS. We limited ourselves to the point particle approach due to two main reasons. Firstly, the three-dimensional (3-D) physics-based fire models are computationally expensive and are not applicable at a scale of more than a few hundred meters in area (Ronchi et al., 2017). Secondly, the application fire models like PHOENIX, SPARK, and FARSITE are operated at a square grid size of $15-30 \mathrm{~m}^{2}$ providing a sufficient acceptable limit (Ronchi et al., 2017). Hence, various commonly used drag models in the literature are tested to improve the spatial distribution of cubiform, cylindrical, and square disc non-burning particles without making a major change in FDS to reduce its computation speed and finding an alternate drag model effective on different isometric shapes. The drag models tested in the present work are: Haider \& Levenspiel (1989), Ganser (1993), Hölzer \& Sommerfeld (2008), Bagheri \& Bonadonna (2016).

\section{DRAG MODELS}

Table 1, gives brief details of the inbuilt FDS drag model for spherical (used for cubiform particles in (Wadhwani et al., 2017) and in this study) (Equation 1) and cylindrical (Equation 2) particles, and the drag models available in the literature for isometric particles. The detailed discussion about each alternative drag model can be found in their respective references. There is no inbuilt drag model in FDS for disc-shaped particles, and hence only the alternative models are tested for square disc particles for their efficacy. 
Haider \& Levenspiel (1989) developed an empirical model (Equation 3) for non-spherical shapes valid in the Stokes' and Newtonian flow region. The Stokes' region corresponds to laminar flow conditions while the Newtonian corresponds to turbulent flow conditions. The drag model was developed from the experimental data published in the literature for different shapes and particle Reynolds' number $\left(R e_{D}\right)$. The particle shape factor is accounted by sphericity $(\psi)$ of the particles. Sphericity is defined as the ratio of the surface area of a given particle to the surface area of a sphere of the same volume. Ganser extended the work of Haider \& Levenspiel in the Ganser drag model (1993) (Equation 4) which accommodates the shape factor in two different flow regimes, one for the Stokes' region and other for the Newtonian region. However, Hölzer \& Sommerfeld (2008) observed that the above two model shows a mean deviation in predicting drag coefficient for disc or plate particles up to $2000 \%$ and for cubiform and cylindrical particles up to $40 \%$, thereby providing two similar drag models. These account for the effect of the tumbling of isometric and non-isometric particles in terms of crosswise and lengthwise sphericity. Hölzer \& Sommerfeld (2008) showed that a mean error using their model in predicting the drag coefficient of disc or plate particles was $\sim 17 \%$ and $\sim 30 \%$ for cubiform and cylindrical particles. They suggested equation 5 (in Table 1), with little loss of accuracy in predicting the drag coefficient, because it is complicated to measure lengthwise sphericity when the particle is moving. In addition, Ganser (1993) suggested that the crosswise sphericity $\psi_{\perp}$ is unity for isometric particles. Hence, in our cases, we used this value in our Hölzer and Sommerfeld model (Equation 5).

Table 1. List of drag models tested in this work

\begin{tabular}{|c|c|c|}
\hline Sr. No. & Drag model & Drag correlation \\
\hline 1 & $\begin{array}{l}\text { FDS Spherical drag } \\
\text { model (McGrattan } \\
\quad \text { et al., 2015) }\end{array}$ & $C_{D, s p h}=\left\{\begin{array}{cl}\frac{24}{\operatorname{Re}_{\mathrm{D}}} & , \operatorname{Re}_{\mathrm{D}}<1 \\
\frac{24\left(0.85+0.15 \mathrm{Re}_{\mathrm{D}}^{0.687}\right)}{\operatorname{Re}_{\mathrm{D}}} & , 1<\operatorname{Re}_{\mathrm{D}}<1000 \\
1 & , \operatorname{Re}_{\mathrm{D}}>1000\end{array}\right.$ \\
\hline 2 & $\begin{array}{l}\text { FDS Cylindrical } \\
\text { drag model } \\
\text { (McGrattan et al., } \\
\text { 2015) }\end{array}$ & $C_{D, c y l}=\left\{\begin{array}{cc}\frac{10}{\operatorname{Re}_{D}^{0.8}}, \quad \operatorname{Re}_{\mathrm{D}}<1 \\
\frac{10\left(0.6+0.4 \mathrm{Re}_{\mathrm{D}}^{0.8}\right)}{\operatorname{Re}_{\mathrm{D}}}, 1<\operatorname{Re}_{\mathrm{D}}<1000 \\
1, \quad \operatorname{Re}_{\mathrm{D}}>1000\end{array}\right.$ \\
\hline 3 & $\begin{array}{l}\text { Haider \& } \\
\text { Levenspiel drag } \\
\text { model (1989) }\end{array}$ & $\begin{array}{l}C_{D, H a}=\frac{24}{\operatorname{Re}_{D}}\left(1+\operatorname{ARe}_{D}^{B}\right)+\frac{C}{1+\frac{D}{\operatorname{Re}_{D}}}, \operatorname{Re}_{D}<2 \times 10^{5} \\
\text { where } \\
A=\exp \left(2.3288-6.4581 \psi+2.4486 \psi^{2}\right), B=0.0964+0.5565 \psi \\
C=\exp \left(4.905-13.8944 \psi+18.4222 \psi^{2}-10.2599 \psi^{3}\right) \\
D=\exp \left(1.4681+12.2584 \psi-20.7322 \psi^{2}+15.8855 \psi^{3}\right)\end{array}$ \\
\hline 4 & $\begin{array}{l}\text { Ganser drag model } \\
(1993)\end{array}$ & $\begin{array}{l}\frac{C_{D, G a}}{K_{2}}=\frac{24}{\operatorname{Re}_{D} K_{1} K_{2}}\left(1+0.1118\left(\operatorname{Re}_{D} K_{1} K_{2}\right)^{0.6567}\right)+\frac{0.4305}{1+\frac{3305}{\mathrm{Re}_{D} K_{1} K_{2}}}, \operatorname{Re}_{D} K_{1} K_{2} \leq 10^{5} \text { (Eq. 4) } \\
\text { where } \\
K_{1} \& K_{2} \text { is Shape factor in Stoke's and Newton regimes } \\
\text { For isometric particle, } K_{1}=\left[0.3333+0.6667 \psi^{-0.5}\right]^{-1} \text { and } K_{2}=10^{1.8148(-\log \psi)^{0.5743}}\end{array}$ \\
\hline 5 & $\begin{array}{l}\text { Hölzer \& } \\
\text { Sommerfeld drag } \\
\text { model (2008) }\end{array}$ & $\begin{array}{l}C_{D, H o}=\frac{8}{\operatorname{Re}_{D} \sqrt{\psi_{\perp}}}+\frac{16}{\operatorname{Re}_{D} \sqrt{\psi}}+\frac{3}{\sqrt{\operatorname{Re}_{D}} \psi^{0.75}}+0.4210^{0.4(-\log \psi)^{0.2}} \frac{1}{\psi_{\perp}}, \operatorname{Re}_{D} \leq 10^{7} \text { (Eq. 5)) } \\
\text { where } \\
\psi_{\perp} \text { is called as a crosswise sphericity }\end{array}$ \\
\hline 6 & $\begin{array}{c}\text { Bagheri \& } \\
\text { Bonadonna drag } \\
\text { model (2016) }\end{array}$ & $\begin{array}{l}\mathrm{C}_{\mathrm{D}, \mathrm{Ba}}=\frac{24 \mathrm{k}_{\mathrm{S}}}{\operatorname{Re}_{\mathrm{D}}}\left(1+0.125\left(\operatorname{Re}_{\mathrm{D}} \frac{\mathrm{k}_{\mathrm{N}}}{\mathrm{k}_{\mathrm{S}}}\right)^{2 / 3}\right)+\frac{0.46 \mathrm{k}_{\mathrm{S}}}{1+\frac{5330}{\operatorname{Re}_{\mathrm{D}} \frac{\mathrm{k}_{\mathrm{N}}}{\mathrm{k}_{\mathrm{S}}}}}, \mathrm{Re}_{\mathrm{D}}<3 \times 10^{5} \\
\text { where } \\
\mathrm{k}_{\mathrm{S}}=\frac{\left(\mathrm{F}_{\mathrm{S}}^{1 / 3}+\mathrm{F}_{\mathrm{S}}^{-1 / 3}\right)}{2}, \mathrm{k}_{\mathrm{N}}=10^{\alpha_{2}\left[-\log \left(\mathrm{F}_{\mathrm{N}}\right)\right] \beta_{2}}, \alpha_{2}=0.45+\frac{10}{\exp \left(2.5 \log \left(\rho^{\prime}\right)+30\right)}, \\
\beta_{2}=1-\frac{37}{\exp \left(3 \log \left(\rho^{\prime}\right)+100\right)}, \text { apparent density }\left(\rho^{\prime}\right)=\frac{\rho_{\text {solid, particle }}}{\rho_{\text {fluid, air }}}, \mathrm{F}_{\mathrm{S}}=\mathrm{fe}^{1.3} \frac{\mathrm{d}_{\text {eq }}^{3}}{\mathrm{LI} \mathrm{S}} \\
\mathrm{F}_{\mathrm{N}}=\mathrm{f}^{2} \mathrm{e} \frac{\mathrm{d}_{\text {eq }}^{3}}{\mathrm{LIS}}, \text { fatness }(\mathrm{f})=\mathrm{S} / \mathrm{I}, \text { elongation }(\mathrm{e})=\mathrm{I} / \mathrm{L}\end{array}$ \\
\hline
\end{tabular}

Bagheri and Bonadonna (2016), takes another step forward on top of the Hölzer and Sommerfeld drag model. Bagheri and Bonadonna averaged the effect of crosswise and lengthwise sphericity to account for the drag model to keep the drag model similar to the Ganser drag model. Hence, this reduces the requirement of estimating crosswise and lengthwise sphericity with time. In the Bagheri and Bonadonna model; equation 6, $d_{e q}$ is the equivalent diameter of the sphere which has the same volume of the particle. $L, I$, and $S$ are the longest, intermediate and shortest length of the particle. Blott and Pye (2008) have discussed how to estimate $L, I$, and $S$ which is used in Bagheri and Bonadonna drag model (Equation 6). 


\section{METHOD}

\subsection{Experimental}

The drag models are appraised against laboratory-scale experiments conducted using a firebrand generator prototype constructed in our facility and detailed in our previous work (Wadhwani et al., 2017). The prototype produces a uniform flow profile with centreline flow velocity at the mouth of $29.5 \mathrm{~m} / \mathrm{s}$ to eject non-burning cubiform, cylindrical, and square disc particles of $10 \mathrm{~mm}$ nominal size. The measurement grid for particle collection is of $20 \mathrm{~cm}$ size (Fig. 1) which will reduce the tumbling effect of the particles on the distribution. The particle distribution and their component velocities are measured using a $720 \mathrm{p}$ at $120 \mathrm{fps}$ camera. The components of particle velocity ( $\mathrm{u}, \mathrm{v}$, and $\mathrm{w}$ ) are measured by displacement of the centroid of particle steak using particle tracking velocimetry (PTV) (Maas et al., 1993).

The particles tested are (i) cubiform: avg. length of $12.45 \mathrm{~mm}$, and mass of $0.83 \mathrm{~g}(0.12 \mathrm{~g} \mathrm{std}$. dev.), (ii) cylindrical: avg. length $11.6 \mathrm{~mm}$, diameter $6.2 \mathrm{~mm}$, and mass of $0.17 \mathrm{~g}(0.01 \mathrm{~g}$ std. dev.), and (iii) square disc: avg. length $10.18 \mathrm{~mm}$, thickness $2.22 \mathrm{~mm}$, and mass of $0.12 \mathrm{~g}(0.01 \mathrm{~g}$ std. dev.). These particles are injected into the firebrand generator at a rate of 0.33 particles/sec. The spatial distributions of particles are measured using particle imaging, and their first impact location is noted (Wadhwani et al., 2017). The final distribution of particles is ignored due to a collision between particles and surface which will be complicated to account for the simulation.

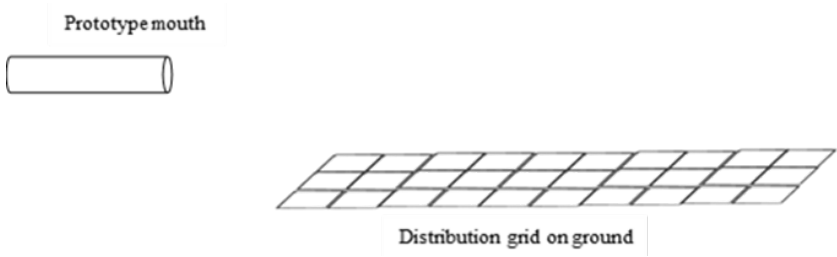

Figure 1. Experimental rig to study the spatial distribution of particles from the prototype (Wadhwani et al., 2017)

\subsection{Numerical Modelling}

Simulation of experimental scenario is carried out using FDS 6.2.0. The domain of the simulation is $7 \mathrm{~m}$ long, $1.2 \mathrm{~m}$ wide, and $2 \mathrm{~m}$ high respectively in X-, Y-, and Z- directions. The simulation domain is sub-divided into four sections (Fig. 2), $x=0-0.5,0.5-1.5,1.5-2.5$, and 2.5-7 m with uniform grid sizes $(\Delta x=\Delta y=\Delta z) 5,10,20$, and $40 \mathrm{~mm}$ respectively. To represent experimental work accurately, six simulation particles densities $(\bar{\mu} \pm$ $\sigma / 4, \bar{\mu} \pm 3 \sigma / 4$, and $\bar{\mu} \pm 5 \sigma / 4 ; \bar{\mu}, \sigma$ is the mean density and the standard deviation of particle densities respectively) are used to represent the particles used in the experiment. The mean and standard deviation of cubiform, cylindrical, and square disc particle densities are 428.3, 492.9, 512.5, 48.9, 44.3, and $35.9 \mathrm{~kg} / \mathrm{m}^{3}$ respectively.

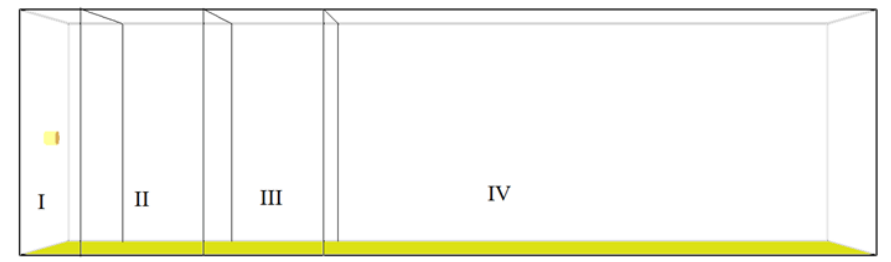

Figure 2. FDS simulation domains to simulate particle distribution divided into four sections (Wadhwani et al., 2017)

\section{RESULTS}

The experimental distribution of the particles (cubiform, cylindrical, and square disc) at the mouth of pipe in two orthogonal directions of the flow is shown in Fig. 3. The distribution is almost uniform at the mouth of the prototype. Although, the distribution is slightly skewed in the Z-direction for cubiform particles due to the weight of the individual particle. The distribution is approximately a normal distribution due to the very low loading rate of the particles. The measured components of particle velocities for cubiform particles are 12.5, $0.0,0.0 \mathrm{~m} / \mathrm{s}$ respectively, with std. dev. of $0.8,0.6$ and $0.6 \mathrm{~m} / \mathrm{s}$ respectively. Similarly, for cylindrical particles, components of particle velocities are 13.4, $0.2,0.2 \mathrm{~m} / \mathrm{s}$ respectively, with std. dev. of $0.9,0.7$ and $0.8 \mathrm{~m} / \mathrm{s}$ respectively; $13.2,0.0,0.0 \mathrm{~m} / \mathrm{s}$, respectively, are components of particle velocities for square disc particles with std. dev. $1.1,0.9,1.1 \mathrm{~m} / \mathrm{s}$ respectively. 


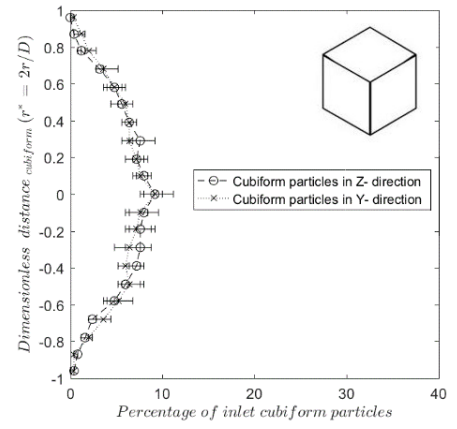

(a) cubiform (Wadhwani et al., 2017)

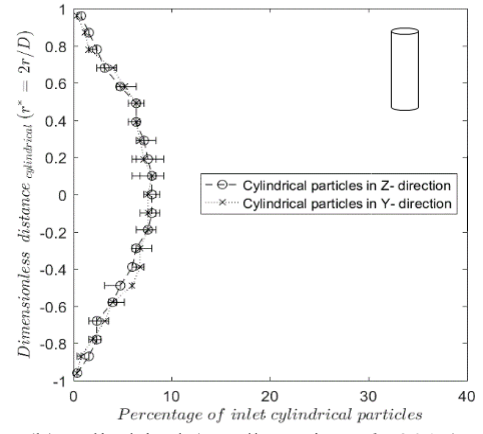

(b) cylindrical (Wadhwani et al., 2017)

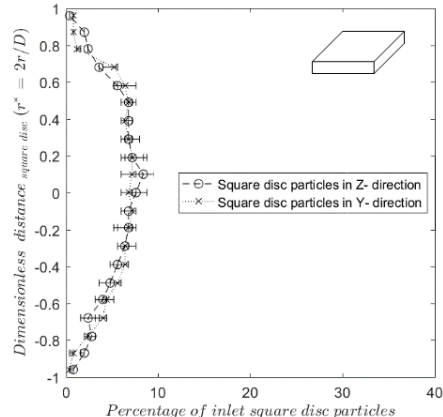

(c) square disc

Figure 3. Distribution of the particles at the mouth of the prototype generator

Fig. 4 shows the comparative contours of simulated and experimental spatial distribution for cubiform particles with different drag models. From Fig. 4(a) we see that for cubiform particles the default FDS drag model for spherical particles provides the best fit with the experimental observation which can be seen with a lower value of the difference between experimental and simulated peak and overlap of lateral spread. The cubiform particle has a minimal tumbling effect due to regular shape in all three directions which has less impact on the drag coefficient. Moreover, the alternative model used for cubiform particles tends to further under-predict the distribution as compared to the spherical drag model which may be due to over-estimation of drag coefficients by respective drag model. Hölzer and Sommerfield (2008) estimated that the drag coefficient computed using Haider and Levenspiel, Ganser, and their own models have a mean error of $42.3 \%, 38.4 \%$, and $27.2 \%$ respectively with experimental data. This could be one reason for such observation in our study. The lateral spread of cubiform particles is found to consistent with all the drag model and found to overlap with the experimental distribution.

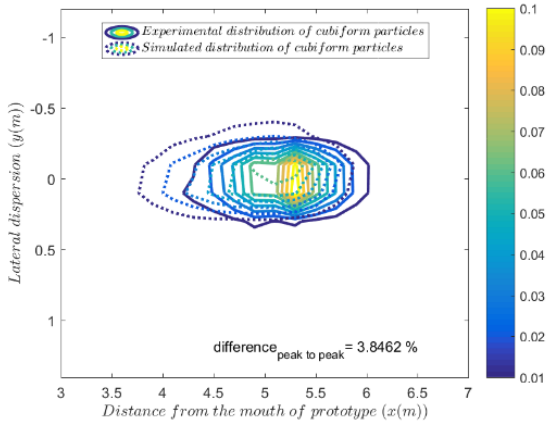

(a) FDS default drag model (Wadhwani et al., 2017)

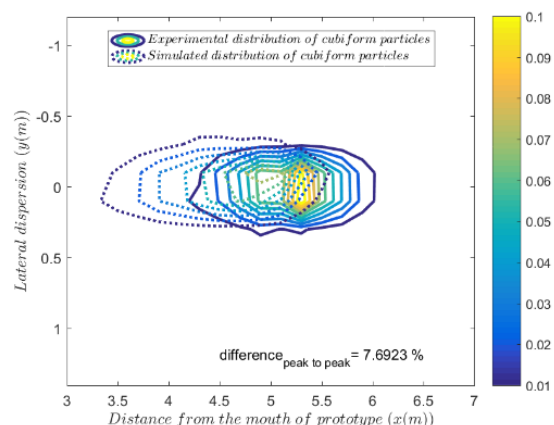

(b) Haider and Levenspiel drag model

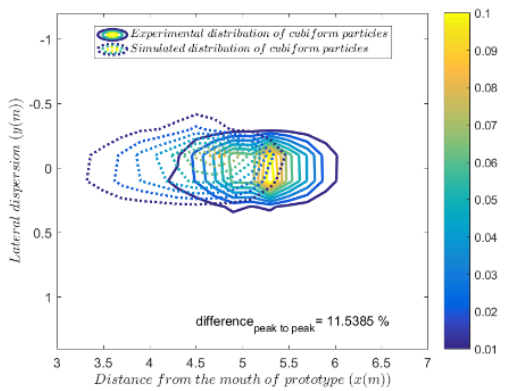

(c) Ganser drag model

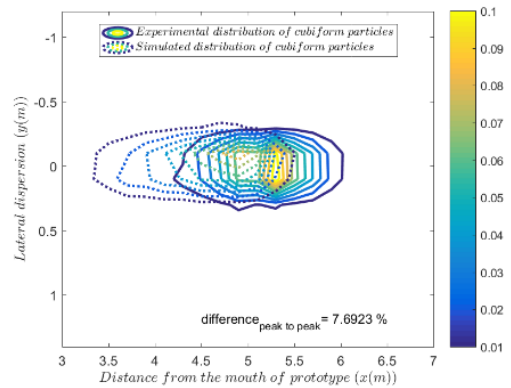

(d) Hölzer and Sommerfeld drag model

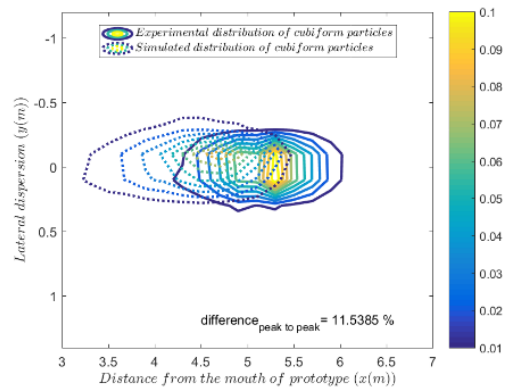

(e) Bagheri and Bonnadonna drag model

Figure 4. Spatial distribution of cubiform particles with different drag models

For particles shaped like a cylindrical and square disc, the tumbling and secondary motion plays a significant role during their transport. It can be seen for cylindrical particles in Fig. 5 and the square disc in Fig. 6 shows more lateral spread as compared to cubiform particles in Fig. 4 which can be seen from their peak intensity. For cylindrical particles, the difference between the peak location of simulation and experiment was reduced when alternative drag models were tested (the minimum was achieved with the Haider and Levenspiel model) as compared to FDS inbuilt model. However, there was no significant change in improving the lateral spread which is anticipated as the particles are assumed to be point particles with no secondary motion at their axis. The lateral spread is found to be $\sim 5-15 \%$ thinner than its experimental lateral spread. Similarly, for square disc particles, only alternative drag models are tested (Fig. 6) as FDS do not have any inbuilt feature to represent such particles. The alternative drag model found to have a reasonable estimation of the peak location with 
Bagheri and Bonadonna model shows the minimum difference in the peaks. The computational domain limits restricts the domain between -0.6 to $0.6 \mathrm{~m}$ (in Fig. 2), bounds the comparison of lateral spread with their experimental observations, thus, also affecting the simulated peak intensity.

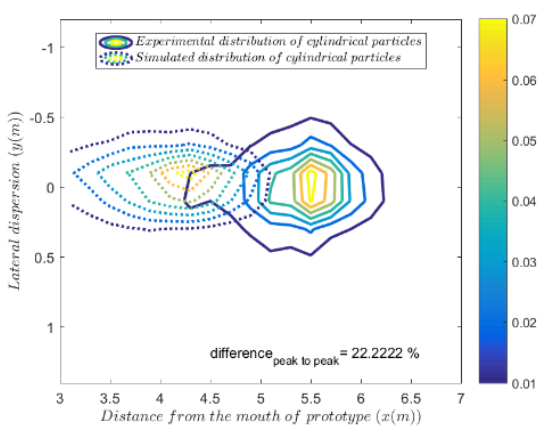

(a) FDS default drag model (Wadhwani et al., 2017)

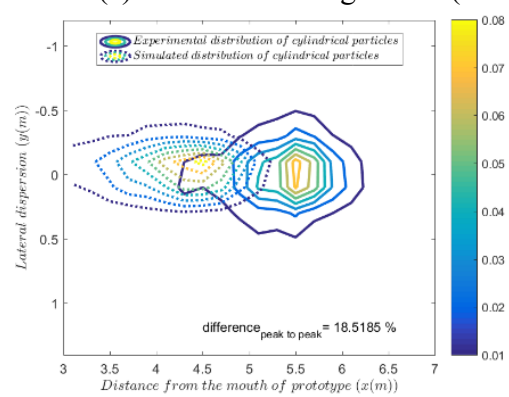

(c) Ganser drag model

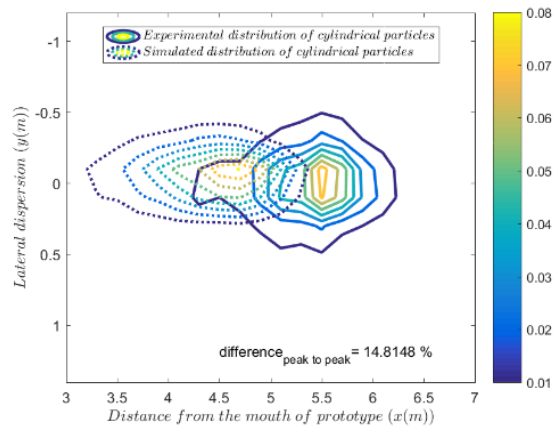

(b) Haider \& Levenspiel drag model

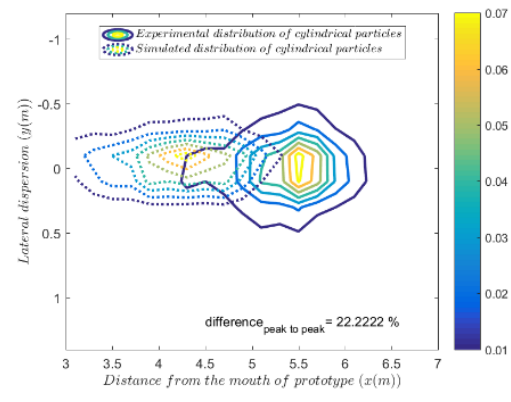

(d) Hölzer and Sommerfeld drag model

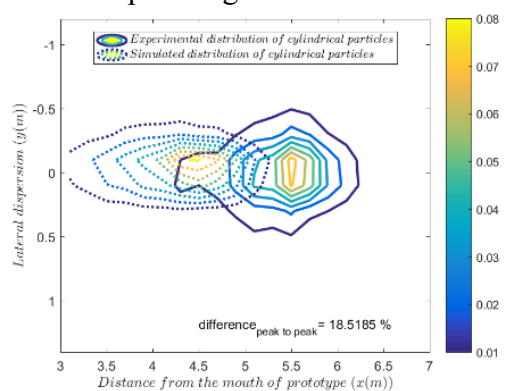

(e) Bagheri and Bonnadonna drag model

Figure 5. Spatial distribution of cylindrical particles with different drag models

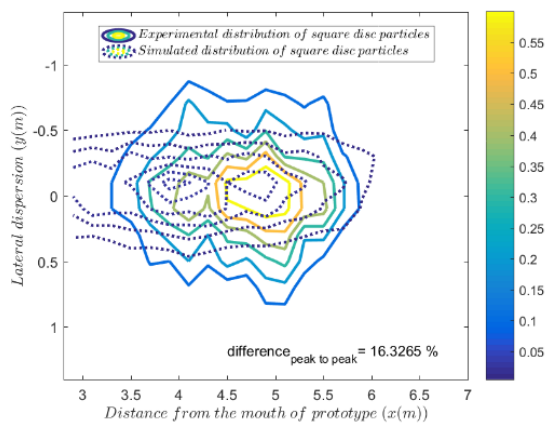

(a) Haider and Levenspiel drag model

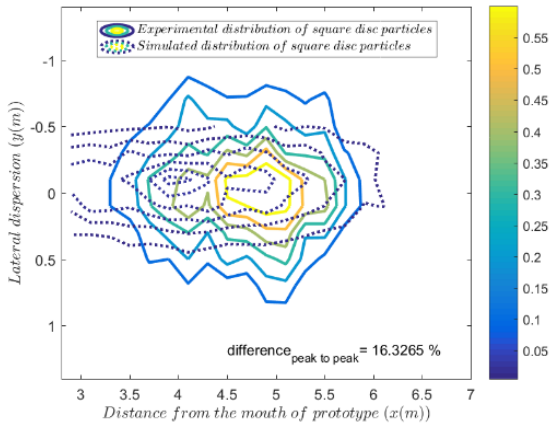

(c) Hölzer and Sommerfeld drag model

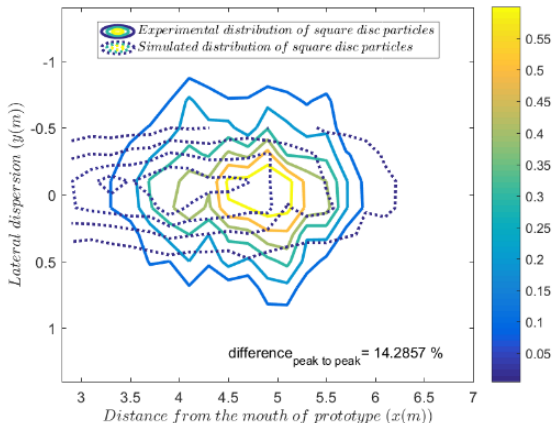

(b) Ganser drag model

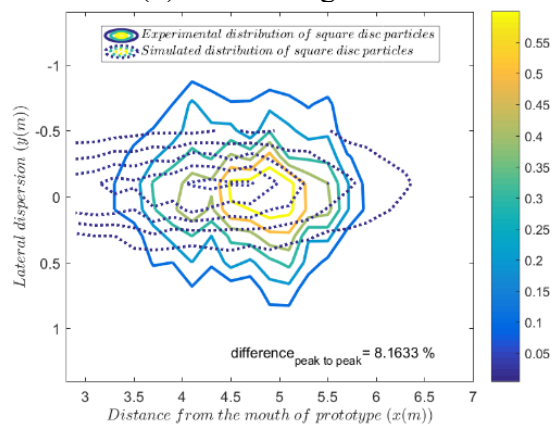

(d) Bagheri and Bonnadonna drag model

Figure 6. Spatial distribution of square disc particles with different drag models

\section{CONCLUSION}

A combined experimental and numerical study is conducted to find an alternative particle drag model which can be utilised to improve the prediction of physics-based fire models such as FDS with the point particle assumption for non-burning firebrands. Using a prototype firebrand generator and various measurement techniques a number of parameters are measured such as fluid velocity, particle velocity components at the mouth and distribution of particles at the mouth. These data are used as input parameters for FDS. Particle landing distributions are also measured and compared with a physics-based model. Three different non-burning 
firebrands (particle) shapes were used: cubiform, cylindrical, and square disc shapes. Four different drag models were implemented into the physics-based model, FDS: Haider and Levenspiel, Ganser, Hölzer and Sommerfeld and Bagheri and Bonnadonna, besides FDS's inbuilt drag model.

The result shows the application of all four alternative drag models generally improve the prediction of nonburning firebrands' distribution and keep the simulated error under the tolerance level. The improvement in landing distribution is achieved without the loss of any computational speed. The alternative drag models, especially Haider \& Levenspiel, reduced the difference between the experimental and simulated experimental cases except for cubiform particles. This exception is due to the minimal secondary motion effect of cubiform particles and the inherent inaccuracy of drag models of over-estimating the drag coefficient. For particles like cylindrical and square disc shapes, where secondary motion is an important part of the motion, a significant improvement is observed in longitudinal direction. However, it is also observed that the existing point particle assumption of FDS is not suited to estimate the lateral spread of firebrands especially when the secondary motion of a particle on its axis is involved such as cylindrical and square-disc particles. In our studies, the lateral spread is found to be in the range of $\sim 5-15 \%$ thinner as compared to its experimental width for cylindrical particle distribution. Tumbling of the particles is expected to increase lateral variation in the flight path of a particle, and thus decrease the total distance travelled, resulting in a wider distribution such as observed in experiments. For the square disc, it is not possible to quantify due to the computational limit associated with our present study. In future, it will be necessary to explore the sensitivity of our observations to different sizes, shapes, speeds of particles and burning processes to ascertain the efficacy of a particular drag model for firebrand transport.

\section{ACKNOWLEDGEMENT}

We wish to acknowledge the financial support given by Bushfire and Natural Hazard Cooperative Research Centre, Australia. The authors wish to thank Mr Lyndon Macindoe and Mr Philip Dunn for their support in constructing the firebrand generator prototype at Victoria University. Also, the authors wish to thank the administrative team of the Spartan HPC, the University of Melbourne for their support in running simulations.

\section{REFERENCES}

Bagheri, G., \& Bonadonna, C. (2016). On the drag of freely falling non-spherical particles. Powder technology, 301, 526-544.

Blott, S. J., \& Pye, K. (2008). Particle shape: a review and new methods of characterization and classification. Sedimentology, 55(1), 31-63.

Cruz, M. G., et al. (2015). Guide to Rate of Fire Spread Models for Australian Vegetation: CSIRO Land and Water Flagship, Canberra, ACT and AFAC, Melbourne, VIC.

Ellis, P. F. (2012). A review of empirical studies of fireband behaviour. Melbourne, Australia: Bushfire Cooperative Research Centre.

Fernandez-Pello, A. C. (2017). Wildland fire spot ignition by sparks and firebrands. Fire safety journal, 91, 210.

Ganser, G. H. (1993). A rational approach to drag prediction of spherical and nonspherical particles. Powder technology, 77(2), 143-152.

Haider, A., \& Levenspiel, O. (1989). Drag coefficient and terminal velocity of spherical and nonspherical particles. Powder technology, 58(1), 63-70.

Hölzer, A., \& Sommerfeld, M. (2008). New simple correlation formula for the drag coefficient of non-spherical particles. Powder technology, 184(3), 361-365.

Maas, H., et al. (1993). Particle tracking velocimetry in three-dimensional flows. Experiments in fluids, 15(2), 133-146.

Mahmud, H., et al. (2016). Study of water-mist behaviour in hot air induced by a room fire: Model development, validation and verification. Fire and materials, 40(2), 190-205.

Manzello, S. L., et al. (2020). Role of firebrand combustion in large outdoor fire spread. Progress in Energy and Combustion Science, 76, 100801.

McGrattan, K., et al. (2015). Fire Dynamics Simulator Technical Reference Guide Volume 1: Mathematical Model Gaithersburg, Maryland, USA.

Ronchi, E., et al. (2017). e-Sanctuary: Open Multi-Physics Framework for Modelling Wildfire Urban Evacuation (FPRF-2017-22). Quincy, MA, USA, .

Sullivan, A. L. (2009a). Wildland surface fire spread modelling, 1990-2007. 1: Physical and quasi-physical models. International Journal of Wildland Fire, 18(4), 349-368. doi:10.1071/WF06143

Sullivan, A. L. (2009b). Wildland surface fire spread modelling, 1990-2007. 3: Simulation and mathematical analogue models. International Journal of Wildland Fire, 18(4), 387-403. doi:10.1071/WF06144

Wadhwani, R., et al. (2017). Verification of a Lagrangian particle model for short-range firebrand transport. Fire safety journal, 91, 776-783. 